Article

\title{
Processing and Characterization of Refractory Quaternary and Quinary High-Entropy Carbide Composite
}

\author{
Hanzhu Zhang(1) and Farid Akhtar * \\ Division of Materials Science, Luleå University of Technology, 97187 Luleå, Sweden; hanzhu.zhang@ltu.se \\ * Correspondence: farid.akhtar@ltu.se
}

Received: 10 April 2019; Accepted: 28 April 2019; Published: 6 May 2019

\begin{abstract}
Quaternary high-entropy ceramic (HEC) composite was synthesized from $\mathrm{HfC}, \mathrm{Mo}_{2} \mathrm{C}, \mathrm{TaC}$, and $\mathrm{TiC}$ in pulsed current processing. A high-entropy solid solution that contained all principal elements along with a minor amount of a Ta-rich phase was observed in the microstructure. The high entropy phase and Ta-rich phase displayed a face-centered cubic (FCC) crystal structure with similar lattice parameters, suggesting that $\mathrm{TaC}$ acted as a solvent carbide during phase evolution. The addition of $\mathrm{B}_{4} \mathrm{C}$ to the quaternary carbide system induced the formation of two high-entropy solid solutions with different elemental compositions. With the increase in the number of principal elements, on the addition of $\mathrm{B}_{4} \mathrm{C}$, the crystal structure of the HEC phase transformed from FCC to a hexagonal structure. The study on the effect of starting particle sizes on the phase composition and properties of the HEC composites showed that reducing the size of solute carbide components HfC, $\mathrm{Mo}_{2} \mathrm{C}$, and TiC could effectively promote the interdiffusion process, resulting in a higher fraction of a hexagonal structured HEC phase in the material. On the other hand, tuning the particle size of solvent carbide, $\mathrm{TaC}$, showed a negligible effect on the composition of the final product. However, reducing the $\mathrm{TaC}$ size from -325 mesh down to $<1 \mu \mathrm{m}$ resulted in an improvement of the nanohardness of the HEC composite from $21 \mathrm{GPa}$ to $23 \mathrm{GPa}$. These findings suggested the possibility of forming a high-entropy ceramic phase despite the vast difference in the precursor crystal structures, provided a clearer understanding of the phase transformation process which could be applied for the designing of HEC materials.
\end{abstract}

Keywords: high-entropy ceramic; solid-state diffusion; microstructure; phase evolution; hardness

\section{Introduction}

High-entropy ceramics (HECs), as a new class of ceramic materials, are developed from the concept of high-entropy alloys (HEAs). In HEAs, multiple principal elemental metals are incorporated to form a single phase alloy or multiphase composites [1,2]. With a similar design concept, HECs consist of multiple principal ceramic compounds such as metallic oxides, nitrides or carbides. In recent work, it has been found that the high entropy effect applies in the HECs system consisting of multiple components [3,4]. Solid solution phases that lack long-range order can be formed attributed to the minimization of Gibbs energy. Christina M. Rost et al. [5] fabricated an entropy stabilized oxide that showed a single-phase face-centered cubic (FCC) structure. Single phase solid solutions have been reported in systems like high entropy borides [6] and high entropy carbides [7,8]. Compared with conventional ceramic materials, single phase HECs show superior mechanical properties contributed by the strain strengthening effect from lattice distortion. For example, the high-entropy carbide fabricated by E. Castle et al. [7] exhibited a single phase FCC structure and enhanced hardness (36.1 GPa) compared to all the component carbides. 
Due to the high melting point of ceramic materials, the solid-state pulsed current processing (PCP) is the economically preferable processing route as it offers relatively low sintering temperatures and short sintering times [9]. PCP utilizes pulsed current, directional pressure, and high vacuum during sintering and offers the advantage of providing homogenously densified materials [10,11]. Due to the strong covalent bonding and complex crystal structures of refractory ceramics, the synthesis of high entropy ceramics has been performed with ceramic precursors containing one nonmetal element (for example carbide, nitride or boride) and a similar crystal structure $[6,7,12,13]$ using PCP. The selection approach of the ceramic precursors minimizes the geometrical difference among the starting ceramic precursor materials and achieves a single-phase high-entropy phase during PCP [14].

Our previous work on the high-entropy ceramic composite shows the possibility of forming a single-phase hexagonal structure from carbide precursors with a vast difference in the crystal structures (FCC, hexagonal and rhombohedral) and two nonmetal atoms (carbon and boron), attributing to the independent diffusion of metal and nonmetal atoms during the $\mathrm{PCP}$ processing [14]. However, the phase formation rules in a high-entropy ceramic system are still elusive and how $\mathrm{B}_{4} \mathrm{C}$ influences the diffusion process remains unclear. In order to develop a better understanding of the formation mechanism of the high-entropy ceramic phase, a systematic study was established and conducted in this work. Quaternary HEC composite was processed from four refractory carbides, $\mathrm{HfC}, \mathrm{Mo}_{2} \mathrm{C}$, $\mathrm{TaC}$, and $\mathrm{TaC}$. The phase evolution on $\mathrm{B}_{4} \mathrm{C}$ addition was studied by investigating the microstructure and phase composition of the five-component carbides. Moreover, due to the importance of starting particle size in solid-state diffusion [15], HEC composites were fabricated from precursors with different particle sizes. The effects of tuning the particles size of the solvent and the solute carbides on the microstructure, phase composition, and mechanical properties are discussed.

\section{Materials and Methods}

HfC ( $<1.25 \mu \mathrm{m}$, Sigma Aldrich, Darmstadt, Germany) and ( -325 mesh, American Elements, Los Angeles, LA, USA), $\mathrm{Mo}_{2} \mathrm{C}$ ( -325 mesh, Alfa Aesar, Haverhill, MA, USA) and (2.6 $\mu \mathrm{m}$, Nanografi, Ankara, Çankaya), TaC (-325 mesh, Alfa Aesar, Haverhill, MA, USA) and (1 $\mu \mathrm{m}$, US Research Nanomaterials, Houston, TA, USA), TiC (5 $\mu \mathrm{m}$, H.C. Starck, Munich, Germany) and ( $2 \mu \mathrm{m}$, Alfa Aesar, Haverhill, MA, USA) and $\mathrm{B}_{4} \mathrm{C}(1-7 \mu \mathrm{m}$, Alfa Aesar, Haverhill, MA, USA) were utilized to synthesize high-entropy ceramic composites. Starting materials with different particle sizes were mixed following the designed recipe, with a molar ratio of 2:1:2:2:2. The powder mixture was homogenized in a ball milling machine for two hours, using $4 \mathrm{~mm}$ stainless steel balls as a milling media and a powder to ball mass ratio of 1:5. The homogenized powder mixture was filled into a graphite die with a diameter of $10 \mathrm{~mm}$ and prepressed before sintering. The sintering was conducted in SPS-530ET (Dr. Sinter Spark Plasma Sintering System, Fuji electronic industrial Co., Ltd., Tsurugashima, Japan) in a glovebox. The samples were heated to $1800^{\circ} \mathrm{C}$ with a heating rate of $100^{\circ} \mathrm{C} / \mathrm{min}$ and then held at $1800^{\circ} \mathrm{C}$ for $5 \mathrm{~min}$ under vacuum. A uniaxial pressure of $60 \mathrm{MPa}$ was applied during the process.

Before the microstructure characterization and phase identification, the samples were cold mounted in epoxy and polished following standard metallurgical sample preparation procedures. The microstructure was observed using a Scanning Electron Microscope JSM-IT300 (JEOL, Tokyo, Japan) operating at an acceleration voltage of $15 \mathrm{kV}$. The elemental composition was analyzed using energy dispersive spectrometer (EDS) mounted on JSM-IT300 that was calibrated with Cobalt. X-ray diffraction (XRD) was conducted using an X-ray diffractometer (Empyrean, PANalytical, Malvern, UK) with $\mathrm{Cu}-\mathrm{K} \alpha$ radiation (wavelength $0.154 \mathrm{~nm}$ ). The scanning was performed from 5 to $120^{\circ}$ (2 Theta), with a step size of $0.02^{\circ}$. The XRD data was investigated using the software PANalytical X'Pert HighscorePlus with the PDF-4 database. The nanohardness of sintered HEC composites was determined using an MTS NanoIndenter XP with a Berkovich diamond indenter. The measurements were performed with a maximum load of $100 \mathrm{mN}$ at ambient temperature in air. The force-displacement curves of the indenter were recorded. Due to different phase distribution and grain sizes in the microstructure of the PCP samples, the nanohardness values for sample 4-HEC and 5-HEC were obtained by performing at least 
5 measurements at specific regions based on the optical microscope mounted on MTS NanoIndenter XP, while the hardness values for sample HEC(+) and HEC(fine) were obtained by performing matrixes indentations and calculating the average value from indentations that were not located in porosity.

\section{Results and Discussions}

\subsection{Effect of $B_{4} C$ Addition into (HfMoTaTi)C}

The microstructure of the quaternary $\mathrm{HEC}$ composite (4-HEC) sintered from $\mathrm{HfC}, \mathrm{Mo}_{2} \mathrm{C}, \mathrm{TaC}$, and TiC shows two distinct phases, as shown in Figure 1. The bright phase with a size of $1-5 \mu \mathrm{m}$ is dispersed uniformly in the dark matrix phase in Figure 1b. Based on the energy-dispersive X-ray spectroscopy (EDS) mapping analysis in Figure 1g, the bright phase is rich in Ta whilst the dark phase contains all constitutional elements $\mathrm{Hf}, \mathrm{Mo}, \mathrm{Ta}, \mathrm{Ti}$ and $\mathrm{C}$. Because of the sensitivity of backscattered electron detector (BED) to the atomic number, phases with different densities appear with different contrast in the BED microstructure. The constituent carbides show a vast difference in the densities, from $14.62 \mathrm{~g} / \mathrm{cm}^{3}$ for $\mathrm{TaC}, 12.2 \mathrm{~g} / \mathrm{cm}^{3}$ for $\mathrm{HfC}, 9.18 \mathrm{~g} / \mathrm{cm}^{3}$ for $\mathrm{Mo}_{2} \mathrm{C}$ to $4.93 \mathrm{~g} / \mathrm{cm}^{3}$ for TiC, therefore the consistent contrast of the dark region in the Figure $1 \mathrm{~b}$ implies that it represents the quaternary ceramic phase containing all constitutional elements $\mathrm{Hf}, \mathrm{Mo}, \mathrm{Ta}, \mathrm{Ti}$, and $\mathrm{C}$. The average atomic ratio of each phase obtained by performing EDS point analysis on several point locations are listed in Table 1 . As EDS lacks the accuracy of quantitative analysis of light elements [16], the atomic ratio of the four metals is normalized to Ta. The results show that the bright phase contains Ta and C as the dominating elements and a minor amount of Mo and trace amount of $\mathrm{Hf}$ and Ti, while the dark phase contains all four metal elements with a relatively lower amount of Ta. According to the X-ray diffraction (XRD) data in Figure 1a, the PCP 4-HEC composite consists of two face-centered cubic (FCC) crystal structures with similar lattice parameters $\left(\mathrm{a}_{1}=0.4429 \mathrm{~nm}, \mathrm{a}_{2}=0.4399 \mathrm{~nm}\right)$, as marked in the inset in Figure $1 \mathrm{a}$. The BED microstructure, EDS analysis and XRD data, Figure 1 and Table 1, suggest the formation of high-entropy FCC solid solution containing all constitutional elements. In the previous work on high-entropy ceramic $\mathrm{B}_{4}\left(\mathrm{HfMo}_{2} \mathrm{TaTi}\right) \mathrm{C}$ [14], it has been reported that $\mathrm{TaC}$ has the lowest metal vacancy formation energy among the precursor carbides, thus it acts as the solvent FCC lattice during the formation of the high-entropy phase [7], i.e., constituent atoms except Ta diffuse into the vacancies in the $\mathrm{TaC}$ lattice to form the multicomponent solid solution. Therefore, the Ta-rich phase and the high-entropy phase can be regarded as intermediates in the phase transformation from constitutional carbides to the hexagonal high-entropy ceramic phase. The multicomponent interdiffusion induces $\mathrm{TaC}$ lattice distortion, which in this case results in the reduction in the initial lattice parameter of $\mathrm{TaC}$, $0.4460 \mathrm{~nm}$ (ICDD reference pattern of TaC: No. 03-065-0282). Based on the quantitative results shown in Table 1, the high-entropy phase with higher content of $\mathrm{Hf}, \mathrm{Mo}$, and Ti metal atoms experience intense atomic diffusion compared to the Ta-rich phase. Hence, in the quaternary high-entropy phase, the atomic position exchange between Ta and other metal atoms with similar or smaller atomic radii results in a smaller lattice parameter $(0.4399 \mathrm{~nm})$ than the TaC-rich phase $(0.4429 \mathrm{~nm})$. Furthermore, the high-entropy phase shows a hardness of $28.4 \mathrm{GPa}$, which is $23.5 \%$ higher than that of the Ta-rich phase (23 GPa) as shown in Figure 2, due to the lattice distortion induced strain strengthening effect. This result is in line with the previous reports on high-entropy materials [6,7]. 

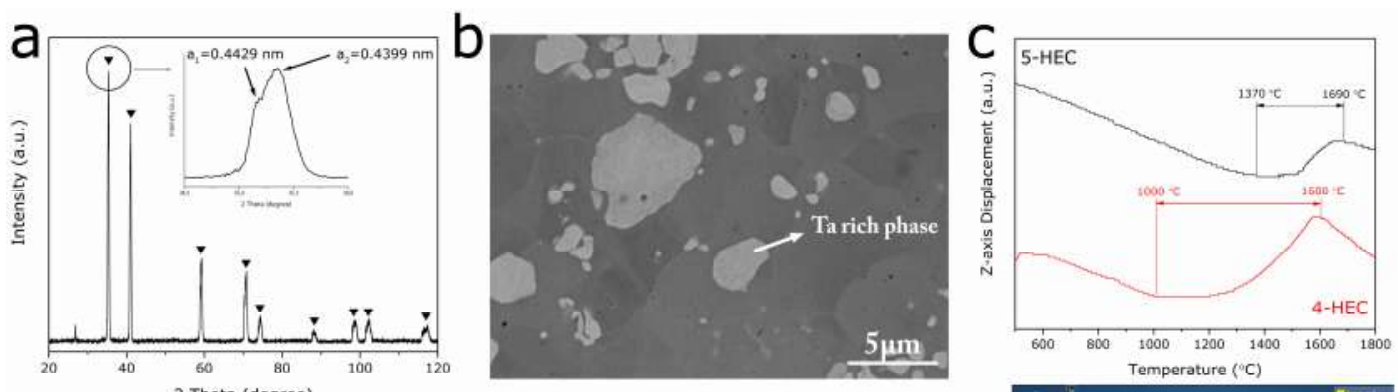

d

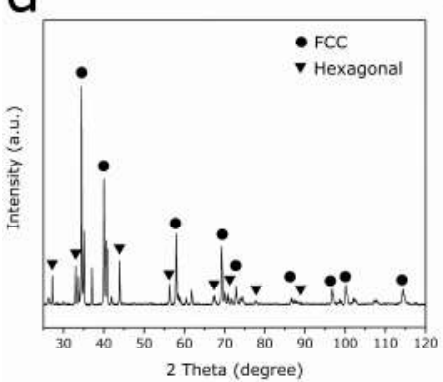

e
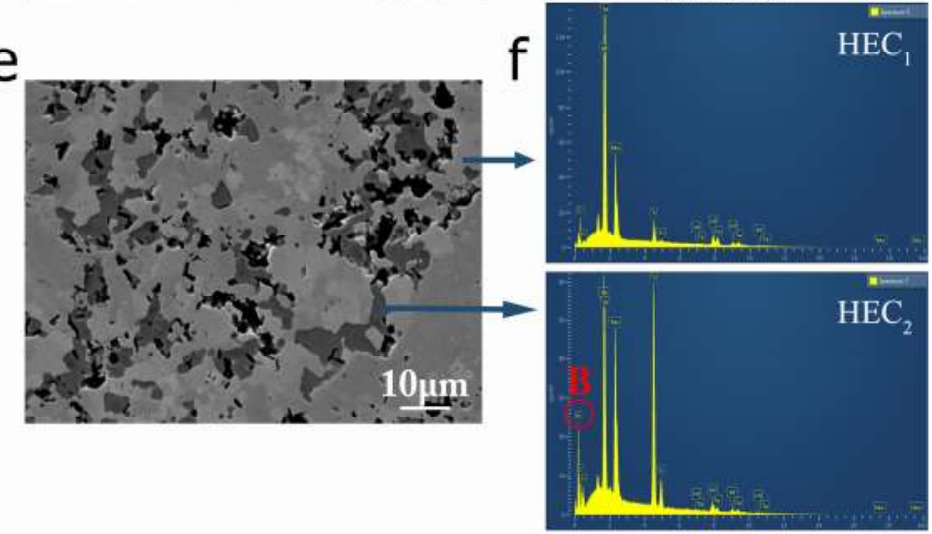

g

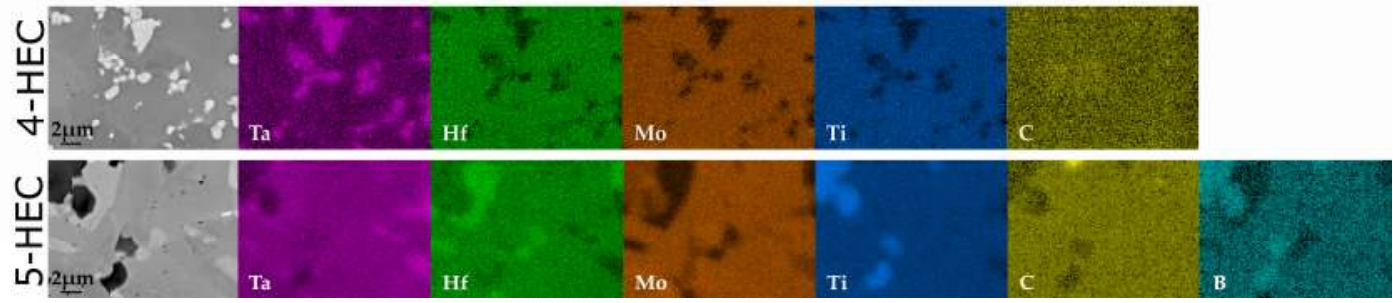

Figure 1. XRD patterns and backscattered electron microstructure of PCP 4-HEC (a,b) and 5-HEC composite (d,e), and the EDS mapping analysis ( $\mathbf{g})$; (c) shows the volume change of the material during sintering; (f) is the EDS qualitative spectra on different phases of 5-HEC.

Table 1. The quantitative analysis of the metal atom contents, the crystal structure identification of different phases in 4-HEC and 5-HEC.

\begin{tabular}{ccccccc}
\hline \multirow{2}{*}{ Compositional Elements } & \multicolumn{2}{c}{ 4-HEC } & \multicolumn{3}{c}{ 5-HEC/HEC(++) } \\
\cline { 2 - 7 } & $\begin{array}{c}\text { Ta-Rich Phase } \\
\text { (Bright) }\end{array}$ & $\begin{array}{c}\text { High-Entropy } \\
\text { Phase (Dark) }\end{array}$ & $\begin{array}{c}\text { Ta-Rich Phase } \\
\text { (Bright) }\end{array}$ & HEC $_{\mathbf{1}}$ (Gray) & HEC $_{\mathbf{2}}$ (Dark) \\
\hline $\mathrm{Hf}$ & - & 2.5 & - & 0.8 & 1.7 \\
$\mathrm{Mo}$ & Minor & 2.4 & Minor & 1.7 & 3.3 \\
$\mathrm{Ti}$ & - & 1.8 & - & 0.6 & 7.7 \\
$\mathrm{Ta}$ & Major & 1 & Major & 1 & 1 \\
\hline Crystal structure & FCC & FCC & FCC & FCC & Hexagonal \\
\hline
\end{tabular}




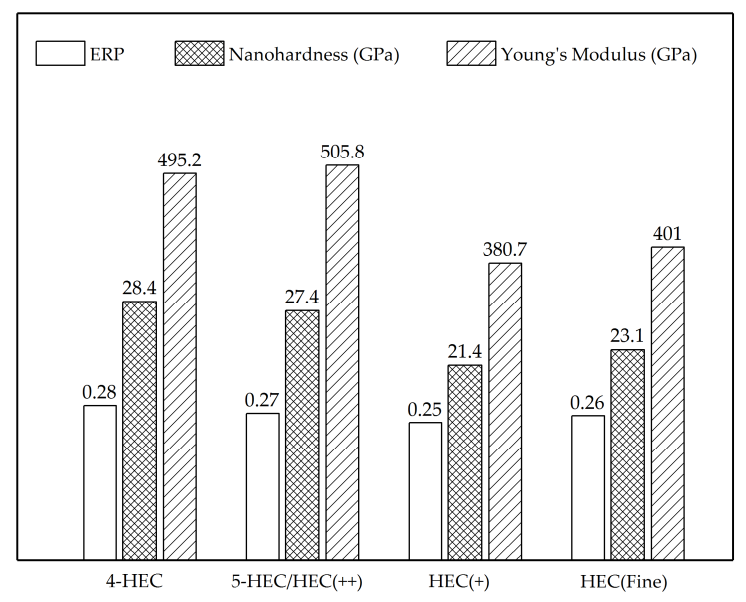

Figure 2. Elastic recovery parameter (ERP), nanohardness and the Young's modulus of the PCP HECs. The nanohardness values refer to the FCC solid solution in 4-HEC, 5-HEC, and average hardness properties for $\mathrm{HEC}(+)$ and $\mathrm{HEC}($ Fine).

The curve of $Z$-axis displacement as a function of temperature was recorded during the PCP. As shown in Figure 1c, the decline of $Z$-axis refers to the thermal expansion of the material, while the up-climbing region corresponds to the shrinkage of the bulk volume. The reduction of the volume typically refers to the occurrence of sintering phenomenon where the powder material becomes compacted and forms a densified solid mass. Since the sintering temperature of powder material is normally 2/3-3/4 of the melting point [17], the theoretical sintering temperature for current quaternary refractory carbide mixture should be above $1800^{\circ} \mathrm{C}$. Figure $1 \mathrm{c}$ shows that the shrinkage of the four-component carbide system 4-HEC takes place from $1000{ }^{\circ} \mathrm{C}$ to $1600{ }^{\circ} \mathrm{C}$, while the same phenomenon for the 5 -HEC composite was postponed to a higher temperature range $1370{ }^{\circ} \mathrm{C}-1690{ }^{\circ} \mathrm{C}$. This indicates that the addition of $\mathrm{B}_{4} \mathrm{C}$ to the carbide system hinders the solid-state atomic diffusion required for sintering in the multicomponent carbides, leading to a delay of the formation of the high-entropy ceramic phase. A detailed investigation on the sintering behavior of ceramic precursors to form high-entropy ceramic composites will be reported later, elsewhere.

The addition of $\mathrm{B}_{4} \mathrm{C}$ to the precursor carbides resulted in the formation of multiple phases during PCP. According to the backscattered electron microstructure in Figure 1e, the PCP 5-HEC composite exhibits three distinct phases. Similar to the 4-HEC, the brightest phase in 5-HEC is rich in Ta, which is coordinated with the fact that Ta has the highest atomic number among the constituent elements, therefore, the Ta-rich phase appears as the brightest phase in the BED microstructure. Two high-entropy solid solutions with different elemental compositions were formed in the five-component system, 5-HEC. The atomic ratio of metal atoms $\mathrm{Hf}, \mathrm{Mo}$, Ta and Ti in the gray $\left(\mathrm{HEC}_{1}\right)$ and dark phase $\left(\mathrm{HEC}_{2}\right)$ in Figure $1 \mathrm{e}$ are shown in Table 1, with $\mathrm{HEC}_{2}$ showing higher content of the solute metal atoms (Hf, $\mathrm{Mo}$, and Ti) in the structure. The higher content of Ti in $\mathrm{HEC}_{2}$ agrees more with the darker contrast of $\mathrm{HEC}_{2}$ than $\mathrm{HEC}_{1}$ in the microstructure, as Ti has the smallest atomic number among the constitutional metal elements. According to the bond dislocation enthalpy (BDE) of transition metal carbides at 298 $\mathrm{K}$ [18], Ti-C has the lowest BDE of $423 \pm 30 \mathrm{KJ} / \mathrm{mol}$ among the solute carbides, while Mo- $\mathrm{C}_{2}$ and $\mathrm{Hf}-\mathrm{C}$ have a BDE of 500 and $540 \pm 25 \mathrm{KJ} / \mathrm{mol}$, respectively, and the covalent atomic radii vary as $\mathrm{Ti}<\mathrm{Mo}<$ Hf. These factors might contribute to preferable diffusion of Ti over Mo and Hf during the formation of the multicomponent solid solution, resulting in the metal content ratio in $\mathrm{HEC}_{2}$ phase as $\mathrm{Ti}>\mathrm{Mo}$ $>\mathrm{Hf}$ in Table 1. A pronounced boron diffraction peak in the EDS pattern was revealed at the $\mathrm{HEC}_{2}$ phase (Figure 1f), suggesting that $\mathrm{HEC}_{2}$ experienced a more intensive diffusion of $\mathrm{B}$ atoms than $\mathrm{HEC}_{1}$. Additionally, the diffractions peaks of $\mathrm{B}_{4} \mathrm{C}$ were not detected in the XRD diffractogram of the 5-HEC composite in Figure 1d, suggesting the participation of $\mathrm{B}_{4} \mathrm{C}$ in the formation of high-entropy solid solutions. However, the diffusion priority of Ti, Mo and Hf was not observed in the high-entropy 
phase in the 4-HEC composite and $\mathrm{HEC}_{1}$ phase in 5-HEC, suggesting that the incorporation of $\mathrm{B}_{4} \mathrm{C}$ to the transition metal carbides might have promoted the diffusion process of the metal atoms towards a more energetically favorable state.

The XRD data in Figure 1d shows that the 5-HEC composite contains both FCC and hexagonal structured phases. Similar with the 4-HEC, the FCC pattern is generated from diffraction of two FCC crystal structures with similar lattice parameters, including the presence of an FCC Ta-rich phase. Based on the aforementioned discussions, the $\mathrm{HEC}_{1}$ phase that contains a lower content of the solute atoms should have a closely-matched crystal structure and lattice constant with the solvent TaC lattice due to the reduced atomic position change in the host lattice corresponding to an FCC structure, while the $\mathrm{HEC}_{2}$ phase corresponds to the hexagonal structure. The $\mathrm{HEC}_{1}$ phase shows a lattice parameter of $0.4499 \mathrm{~nm}$, which is slightly greater than that of $\mathrm{TaC}(0.4460 \mathrm{~nm})$. Assuming that the $\mathrm{HEC}_{1}$ is formed from only transition metal carbides, the lattice parameter should decline as observed in the FCC high-entropy solid solutions in 4-HEC composite (Figure 1a). It is known that the metal-boron bond length is longer than metal-carbon bond length, for example, Ta-C $=2.22 \AA$ [19] and Ta-B $=2.41$ $\AA$ [20], the expansion of the lattice can be contributed by the addition of $B$ atoms in the formation of an $\mathrm{HEC}_{2}$ solid solution. The formation of high-entropy solid solutions $\mathrm{HEC}_{1}$ and $\mathrm{HEC}_{2}$ that contain all constitutional elements confirms the possibility of processing high-entropy ceramics from a precursor system containing more than one nonmetal atoms and with different crystal structures. The formation of hexagonal structure is likely to be attributed to more B atoms diffusing in the FCC lattice, which induces more severe lattice distortion and consequently leads to the crystal structure change from FCC to a hexagonal structure. In the 5-HEC composite, the FCC structured $\mathrm{HEC}_{1}$ solid solution shows a nanohardness of $27.4 \mathrm{GPa}$ and Young's modulus of $505.8 \mathrm{GPa}$, which is close to the FCC solid solution phase in 4-HEC (28.4 GPa and 495.2 GPa for nanohardness and Young's modulus, respectively).

\subsection{Effect of Different Starting Particle Sizes}

It is well known that the particle size of the precursors is an essential parameter influencing the atomic diffusion and phase evolution during solid-state sintering in PCP [15]. Fine particles promote the solid-state atomic diffusion by reducing the diffusion distance and promote the kinetics of phase transformation [21,22]. To investigate the effect of particle size on the formation of high-entropy ceramics, the same carbide systems with different particle sizes are sintered in PCP (as listed in Table 2). 5-HEC that utilized relative larger particle sizes of solute metal carbides ( $\mathrm{HfC}, \mathrm{Mo}_{2} \mathrm{C}$, and $\mathrm{TiC}$ ) is discussed in the previous section and is denoted as $\mathrm{HEC}(++)$ in the following discussion. HEC(fine) and $\mathrm{HEC}(+)$ contains precursor carbides with the finest particle sizes and a larger particle size of the solvent carbide $(\mathrm{TaC})$, respectively.

Table 2. Precursors with different particle sizes are utilized to study the effect on the phase evolution.

\begin{tabular}{cccc}
\hline Component & HEC(++) & HEC(+) & HEC(Fine) \\
\hline $\mathrm{B}_{4} \mathrm{C}$ & $1-7 \mu \mathrm{m}$ & $1-7 \mu \mathrm{m}$ & $1-7 \mu \mathrm{m}$ \\
$\mathrm{HfC}$ & -325 mesh & $<1.25 \mu \mathrm{m}$ & $<1.25 \mu \mathrm{m}$ \\
$\mathrm{Mo}_{2} \mathrm{C}$ & -325 mesh & $2.6 \mu \mathrm{m}$ & $2.6 \mu \mathrm{m}$ \\
$\mathrm{TiC}$ & $5 \mu \mathrm{m}$ & $2 \mu \mathrm{m}$ & $2 \mu \mathrm{m}$ \\
$\mathrm{TaC}$ & $<1 \mu \mathrm{m}$ & $-325 \mathrm{mesh}$ & $<1 \mu \mathrm{m}$ \\
\hline
\end{tabular}

The microstructure of the PCP HEC(+) and HEC(fine) show the presence of two phases in Figure 3. According to the compositional mapping analysis in Figure $3 \mathrm{~d}$, all four metal elements are distributed in bright and dark phases. The spot-shaped mapping for $C$ is attributed to porosity in the samples, which possibly caused the diamond polishing agents being introduced during the sample preparation procedure. For both PCP HEC(+) and HEC(fine) sample, the bright phase is rich in Ta and Hf while the dark phase contains a greater amount of Mo and Ti. The quantitative analysis results of the selected areas in Table 3 show that these two phases are high-entropy solid solutions with different elemental 
compositions. The average atomic ratios are normalized to Ta. The bright phase is rich in Ta, while the dark phase has a higher content of other metals $(\mathrm{Ti}>\mathrm{Mo}>\mathrm{Hf} \approx \mathrm{Ta}$ ). Based on the discussion about BED microstructure of different transition metal carbides, the dark region with a higher solute metal content refers to more equilibrium composition and a higher extent of phase transformation towards the high-entropy solid solution.
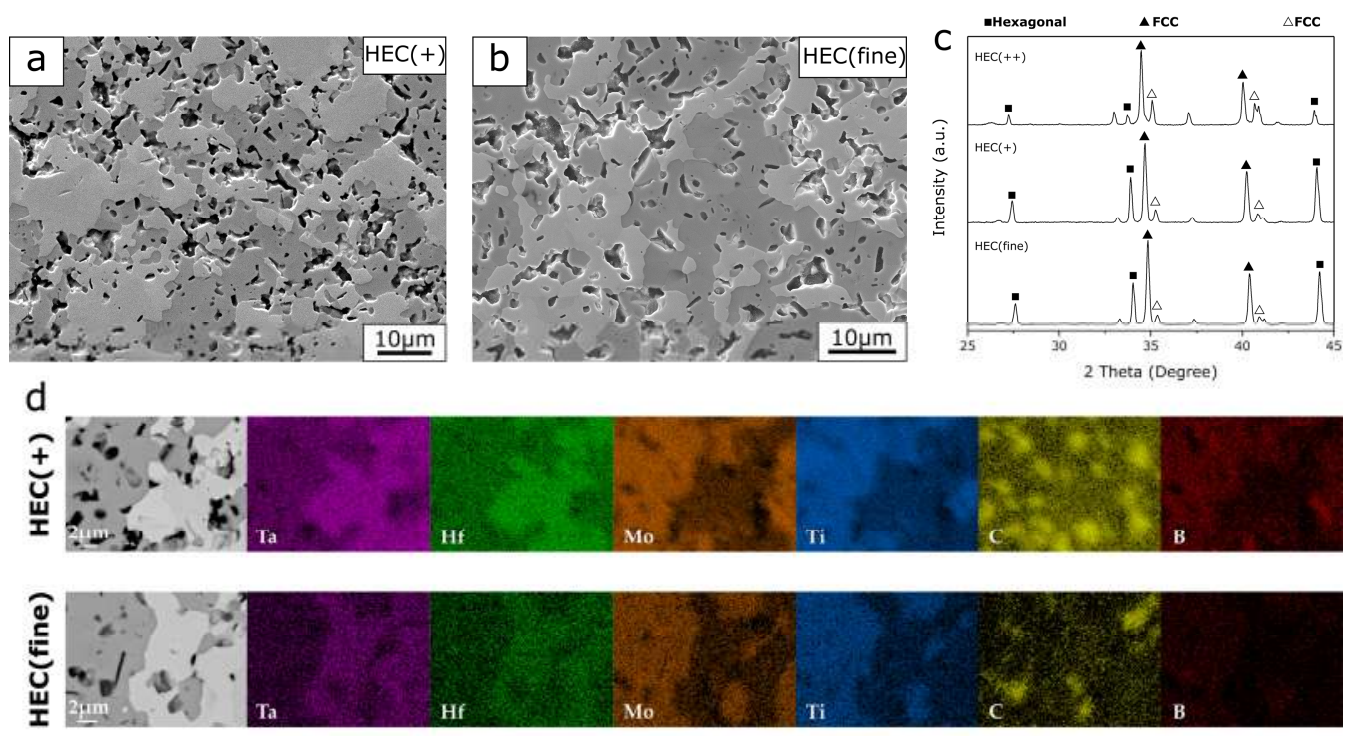

Figure 3. Microstructure $(\mathbf{a}, \mathbf{b})$ and X-ray diffraction phase identification (c) and EDS mapping analysis (d) of PCP HEC(+) and HEC(fine).

Table 3. The quantitative analysis of the metal atom contents of different phases in HEC $(+)$ and HEC(fine).

\begin{tabular}{ccccc}
\hline \multirow{2}{*}{ Compositional Elements } & \multicolumn{2}{c}{ HEC(+) } & \multicolumn{2}{c}{ HEC(fine) } \\
\cline { 2 - 5 } & Bright Phase & Dark Phase & Bright Phase & Dark Phase \\
\hline Hf & 0.4 & 1.2 & 1 & 1.1 \\
Mo & 0.8 & 1.9 & 0.7 & 2.0 \\
$\mathrm{Ti}$ & 0.2 & 2.3 & 0.8 & 2.8 \\
$\mathrm{Ta}$ & 1 & 1 & 1 & 1 \\
\hline Crystal structure & FCC & Hexagonal & FCC & Hexagonal \\
\hline
\end{tabular}

The XRD patterns of HEC(+) and HEC(fine) show high similarity (Figure 3c). Similar to the diffractogram of $\mathrm{HEC}(++)$, the PCP HEC(+) and HEC(fine) composite reveal diffraction patterns from two FCC and one hexagonal structure. Since the elemental mapping from each region with a constant contrast shows a homogenous distribution of constituent elements, a possible reason why the third phase is not distinguishable in the microstructure is that the two FCC phases have indistinguishable contrast in BED images, which suggests that these phases have a similar atomic composition. As the bright phase with less content of foreign atoms (except Ta), it refers to the component with less lattice distortion, therefore it is extrapolated to retain a FCC crystal structure, whilst the dark phase exhibits a hexagonal structure.

For the solid-state phase transformations, the starting particle size has been reported to have a strong influence on the reaction kinetics by tuning the contact area between the solid particles [23-25]. Therefore, it was expected that PCP HEC(fine) with finest starting particle size should have a more promoted phase transformation than $\mathrm{HEC}(+)$ and $\mathrm{HEC}(++)$ which were fabricated with the same sintering route and sintering conditions. Comparing $\operatorname{HEC}($ fine) with $\operatorname{HEC}(+)$, the results show high similarity in the microstructures and phase composition (Figure 3). Both composites consist of a 
FCC and a hexagonal crystal structure, with high-entropy solid solutions. With HfC having the lowest formation enthalpy $(-1.826 \mathrm{eV})[14]$ and highest BDE $\left(9.18 \mathrm{~g} / \mathrm{cm}^{3}\right)$ among the precursors [18], the promotion of the solid-state diffusion can be observed by the increased Hf content in the FCC phase in $\mathrm{HEC}($ fine) than $\mathrm{HEC}(+)(\mathrm{Hf} / \mathrm{Ta}=1$ and 0.4 , respectively) according to the EDS quantitative results in Table 3. On the other hand, $\mathrm{HEC}(++)$ has a complicated phase composition compared to HEC(fine). The Ta-rich phase, representing the least diffusion, was observed in HEC(++) (Figure 1e). A lower fraction of the hexagonal structured high-entropy solid solution in $\mathrm{HEC}(++)$ composite can be concluded from the microstructure and lower intensity of X-ray diffraction peaks (for example at $2 \theta$ $\left.=44.2^{\circ}\right)$ in Figure 3c. Therefore, the degree of diffusion is assumed to be in the order of HEC $(++)<$ $\mathrm{HEC}(+) \approx \mathrm{HEC}($ fine). The results suggest that the particle size of solvent carbide TaC is not as essential as the solute carbides in terms of tailoring the phase composition in the multicomponent carbide system. Due to the porosity and small grain size, the nanoindentation testing of $\mathrm{HEC}(+)$ and $\mathrm{HEC}($ fine) composites were obtained from 30 indentations, therefore the data represents the overall mechanical properties of the bulk materials instead of each individual high-entropy phase. Although the PCP HEC(fine) and HEC(+) show the same phase composition and similar microstructure, the HEC(fine) composite sintered from precursors with finest grain size shows improved nanoindentation hardness of 23.1 GPa compared to the PCP HEC(+) composite (21.4 GPa). The experimental hardness value is close to the theoretical hardness calculated from the rule of mixture (23.2 GPa). The enhancement of the hardness caused by utilizing small starting particle size during sintering has been reported before [26]. Moreover, Young's modulus of HEC(fine) improves from $380.7 \mathrm{GPa}$ for HEC(+) to $401 \mathrm{GPa}$, suggesting stronger atomic bonding in the HEC(fine) composite.

\section{Conclusions}

A high-entropy ceramic (HEC) composite was synthesized from $\mathrm{HfC}, \mathrm{Mo}_{2} \mathrm{C}, \mathrm{TaC}$, and $\mathrm{TiC}$ by pulsed current processing (PCP). The PCP 4-HEC composite contained a high-entropy phase and a Ta-rich phase. Both constituents showed a face-centered cubic (FCC) structure and corresponded to the different extent of phase transformation towards a high-entropy phase. By introducing $\mathrm{B}_{4} \mathrm{C}$ in the HEC composite, high-entropy solid solutions that contained all principal elements (including B) were formed. The high-entropy phase with less intense interdiffusion remained FCC structure as the solvent carbide, $\mathrm{TaC}$, while the one with more complete phase transformation experienced crystal structure change from FCC to a hexagonal structure. The results showed the feasibility of synthesizing HEC materials from the multi-principal ceramic system with different crystal structures.

In order to investigate the effect of different particle sizes of solvent and solute components on the phase composition and properties, HEC composites fabricated from precursors with different size of solvent (TaC) and solute carbides (with face-centered cubic (FCC) structure) were PCP consolidated and characterized. The particle size of the solvent carbides was found to be more essential for the interdiffusion process and final phase compositions than that of the solute carbide. HEC composites processed from the fine particle size of solvent carbides $\mathrm{HfC}, \mathrm{Mo}_{2} \mathrm{C}$, and $\mathrm{TiC}$ showed a higher content of the hexagonal structured HEC phase. On the other hand, reducing the TaC particle size to nanoscale showed negligible influence on the phase composition, but resulted in enhancement of the microhardness from 21.4 GPa to 23.1 GPa.

Author Contributions: Conceptualization, F.A.; methodology, F.A. and H.Z.; formal analysis, H.Z.; investigation, H.Z.; writing-original draft preparation, H.Z.; writing_review and editing, F.A.; supervision, F.A.; project administration, F.A.

Funding: This work was supported by the Swedish Foundation for Strategic Research (SSF) for Infrastructure Fellowship, grant number RIF14-0083.

Conflicts of Interest: The authors declare no conflict of interest. 


\section{References}

1. Manzoni, A.M.; Glatzel, U. New multiphase compositionally complex alloys driven by the high entropy alloy approach. Mater. Charact. 2019, 147, 512-532. [CrossRef]

2. Miracle, D.B.; Senkov, O.N. A critical review of high entropy alloys and related concepts. Acta Mater. 2017, 122, 448-511. [CrossRef]

3. Tsai, M.H.; Yeh, J.W. High-entropy alloys: A critical review. Mater. Res. Lett. 2014, 2, 107-123. [CrossRef]

4. Gao, M.C.; Yeh, J.-W.; Liaw, P.K.; Zhang, Y. High-Entropy Alloys; Springer: Cham, Switzerland, 2016.

5. Rost, C.M.; Sachet, E.; Borman, T.; Moballegh, A.; Dickey, E.C.; Hou, D.; Jones, J.L.; Curtarolo, S.; Maria, J.P. Entropy-stabilized oxides. Nat. Commun. 2015, 6, 8485. [CrossRef] [PubMed]

6. Gild, J.; Zhang, Y.; Harrington, T.; Jiang, S.; Hu, T.; Quinn, M.C.; Mellor, W.M.; Zhou, N.; Vecchio, K.; Luo, J. High-Entropy Metal Diborides: A New Class of High-Entropy Materials and a New Type of Ultrahigh Temperature Ceramics. Sci. Rep. 2016, 6, 37946. [CrossRef] [PubMed]

7. Castle, E.; Csanádi, T.; Grasso, S.; Dusza, J.; Reece, M. Processing and Properties of High-Entropy Ultra-High Temperature Carbides. Sci. Rep. 2018, 8, 8609. [CrossRef] [PubMed]

8. Dusza, J.; Peter, Š.; Girman, V.; Sedlák, R.; Castle, E.G.; Csanádi, T.; Koval, A.; Reece, M.J. Microstructure of (Hf-Ta-Zr-Nb)C high-entropy carbide at micro and nano/atomic level. J. Eur. Ceram. Soc. 2018, 38, 4303-4307. [CrossRef]

9. Munir, Z.A.; Anselmi-Tamburini, U.; Ohyanagi, M. The effect of electric field and pressure on the synthesis and consolidation of materials: A review of the spark plasma sintering method. J. Mater. Sci. 2006, 41, 763-777. [CrossRef]

10. Guillon, O.; Gonzalez-Julian, J.; Dargatz, B.; Kessel, T.; Schierning, G.; Räthel, J.; Herrmann, M. Field-assisted sintering technology/spark plasma sintering: Mechanisms, materials, and technology developments. Adv. Eng. Mater. 2014, 16, 830-849. [CrossRef]

11. Bellosi, A.; Monteverde, F.; Sciti, D. Fast densification of ultra-high-temperature ceramics by spark plasma sintering. Int. J. Appl. Ceram. Technol. 2006, 3, 32-40. [CrossRef]

12. Zhou, J.; Zhang, J.; Zhang, F.; Niu, B.; Lei, L.; Wang, W. High-entropy carbide: A novel class of multicomponent ceramics. Ceram. Int. 2018, 44, 22014-22018. [CrossRef]

13. Demirskyi, D.; Borodianska, H.; Suzuki, T.S.; Sakka, Y.; Yoshimi, K.; Vasylkiv, O. Scripta Materialia High-temperature fl exural strength performance of ternary high-entropy carbide consolidated via spark plasma sintering of TaC, $\mathrm{ZrC}$ and NbC. Scr. Mater. 2019, 164, 12-16. [CrossRef]

14. Zhang, H.; Hedman, D.; Feng, P.; Han, G.; Akhtar, F. A high-entropy $\mathrm{B}_{4}\left(\mathrm{HfMo}_{2} \mathrm{TaTi}\right) \mathrm{C}$ and SiC ceramic composite. Dalt. Trans. 2019, 48, 5161-5167. [CrossRef]

15. Zhang, H.; Feng, P.; Akhtar, F. Aluminium matrix tungsten aluminide and tungsten reinforced composites by solid-state diffusion mechanism. Sci. Rep. 2017, 7, 12391. [CrossRef]

16. Agarwal, B.K. X-ray Spectroscopy: An Introduction; Springer: Berlin/Heidelberg, Germany, 2013; Volume 15, ISBN 3540386688.

17. CDowson, G. Powder Metallurgy: The Process and Its Products; Adam Hilger: Bristol, UK, 1990; ISBN 0852740069.

18. Simões, J.A.M.; Beauchamp, J.L. Transition Metal-Hydrogen and Metal-Carbon Bond Strengths: The Keys to Catalysis. Chem. Rev. 1990, 90, 629-688. [CrossRef]

19. TaC Crystal Structure: Datasheet from "PAULING FILE Multinaries Edition - 2012" in Springer Materials. Available online: https://materials.springer.com/isp/crystallographic/docs/sd_0261184 (accessed on 6 May 2019).

20. TaB2 Crystal Structure: Datasheet from "PAULING FILE Multinaries Edition - 2012" in Springer Materials. Available online: https://materials.springer.com/isp/crystallographic/docs/sd_0260764 (accessed on 6 May 2019).

21. Fick, A. Ueber Diffusion. Ann. Phys. 1855, 170, 59-86. [CrossRef]

22. Malik, R.; Burch, D.; Bazant, M.; Ceder, G. Particle size dependence of the ionic diffusivity. Nano Lett. 2010, 10, 4123-4127. [CrossRef]

23. Ferret, R.; Lo, R.; Gutie, M.A. Influence of particle size distribution of precursor oxides on the synthesis of cordierite by solid-state reaction. Powder Technol. 2005, 153, 34-42.

24. Kim, H.; Kim, J.; Jung, W.; Yoon, D. Effect of starting materials on the properties of solid-state reacted barium titanate powder. J. Ceram. Process. Res. 2009, 10, 753-757. 
25. Buscaglia, M.T.; Bassoli, M.; Buscaglia, V.; Vormberg, R. Solid-State Synthesis of Nanocrystalline $\mathrm{BaTiO}_{3}$ : Reaction Kinetics and Powder Properties. J. Am. Ceram. Soc. 2008, 91, 2862-2869. [CrossRef]

26. Srivatsan, T.S.; Woods, R.; Petraroli, M.; Sudarshan, T.S. An investigation of the influence of powder particle size on microstructure and hardness of bulk samples of tungsten carbide. Powder Technol. 2002, 122, 54-60. [CrossRef] 